\title{
Association of smoking with intraocular pressure in middle-aged and older Japanese residents
}

\author{
Masao Yoshida $\cdot$ Shinichiro Take $\cdot$ Mamoru Ishikawa • \\ Akatsuki Kokaze $\cdot$ Kanae Karita • Matsuko Harada • \\ Hideki Ohno
}

Received: 7 March 2013/Accepted: 8 August 2013/Published online: 28 August 2013

(C) The Japanese Society for Hygiene 2013

\begin{abstract}
Objectives To clarify whether smoking was associated with elevated intraocular pressure (IOP) and to evaluate the interrelationship among IOP, blood viscosity, and smoking. Methods This cross-sectional study analyzed health examination data obtained between 2001 and 2004 from 1113 individuals ( 829 men and 284 women), ranging in age from 28 to 79 years, who had not undergone any ocular surgery or medical treatment for hypertension, ocular hypertension, and glaucoma.

Results Multiple-regression analysis showed that systolic blood pressure (SBP), diastolic blood pressure (DBP), body mass index (BMI), and number of cigarettes smoked per day had a significantly positive association with IOP in men $(P<0.05)$. In women also, SBP, DBP, and BMI were positively related to IOP $(P<0.05)$. On the contrary, age had a significant negative association with IOP in both sexes $(P<0.01)$. Analysis of covariance and multiple
\end{abstract}

M. Yoshida $(\bowtie) \cdot$ S. Take $\cdot$ M. Ishikawa $\cdot$ A. Kokaze ·

K. Karita $\cdot$ M. Harada $\cdot$ H. Ohno

Department of Public Health, Kyorin University School of

Medicine, 6-20-2 Shinkawa, Mitaka-shi, Tokyo 181-8611, Japan

e-mail: yohhy@ks.kyorin-u.ac.jp

S. Take

Saitama Kaisei Hospital, Saitama, Japan

M. Ishikawa

Ningen Dock Clinic Kashiwa, Chiba, Japan

\section{A. Kokaze}

Department of Public Health, Showa University School of Medicine, Tokyo, Japan

M. Harada

Department of Living Science, Teikyo Junior College,

Tokyo, Japan logistic regression analyses showed that the adjusted mean IOP and the multivariate odds ratios for IOP increased with increasing cigarette consumption in men $(P$ for trend $=0.01$ and 0.06 , respectively). Analysis of covariance found that smoking was significantly associated with both high IOP and high hematocrit in men $(P$ for trend $<0.05$ ); however, the adjusted mean IOP values were higher in smokers than in nonsmokers, regardless of the hematocrit level.

Conclusions The results of this study suggested that the IOP level may be substantially affected by smoking habit in middle-aged and older Japanese men.

Keywords Intraocular pressure - Smoking . Epidemiology · Ocular hypertension · Glaucoma

\section{Introduction}

It is well known that smoking is a confirmed risk factor for various cancers, cerebro-cardiovascular diseases, and chronic obstructive pulmonary disease. The World Health Organization declares smoking is one of the most important problems to be solved for our health damages in the world [1]. Although several epidemiological studies have reported the association of smoking with glaucoma [2-6] and elevated intraocular pressure (IOP) [7-11], the role of smoking as a risk factor for them remains controversial. Positive associations of smoking with glaucoma $[2,4,6]$ and elevated IOP $[7,9,11]$ have been found, although other studies have also reported no association of smoking with glaucoma [3,5] and elevated IOP [8, 10].

Ocular hypertension, which is usually defined as IOP higher than normal (IOP $>21 \mathrm{mmHg}$ ) in the absence of optic nerve damage or visual field loss [12], is one of the 
major risk factors for the development of open-angle glaucoma (OAG) [13]. Several studies have reported that relatively high IOP can cause optic-nerve damage and visual-field abnormalities, even if it is within the normal range [14]. High IOP can also affect the progression of visual-field defects in patients with OAG, particularly those with normal tension glaucoma (NTG) $[15,16]$. Clarifying the factors that are associated with increases or decreases in IOP is of particular importance for the Japanese population, which has a higher incidence of NTG; the proportion of NTG for OAG among Japanese and Western populations aged 40 or more is, respectively, 80-90\% [17-19] and 50-60\% [20-22].

Although a positive association have been found between IOP and smoking [7, 9, 11], and between blood viscosity and smoking [23-25], most of these studies were conducted in Western countries [7, 9, 11, 23, 25]. Few epidemiological studies have examined these relationships in a Japanese population. Up to the present, there have been no studies investigating the interrelationship among IOP, blood viscosity, and smoking. Therefore, in the present study, we attempted to clarify whether smoking was associated with elevated IOP and to evaluate the interrelationship between IOP, blood viscosity, and smoking. We analyzed health examination data from middle-aged and older Japanese residents in a prefectural capital close to Tokyo. The results of this study might contribute to preventing the progression of IOP-related optic nerve damage and visual-field defects.

\section{Materials and methods}

\section{Subjects}

A total of 1320 residents of the Ibaraki prefecture, Japan, were examined between April 2001 and March 2004 by means of an annual health check-up at a general hospital in Mito, which is the capital city of the prefecture. From this initial group, 1113 individuals (829 men and 284 women) who had not undergone any ocular surgery or medical treatment for hypertension, ocular hypertension, and glaucoma were selected to participate in the study. The enrolled subjects ranged in age from 28 to 79 years.

This study was conducted in accordance with the Declaration of Helsinki of the World Medical Association and was approved by the human ethics review committees of the Mito Red Cross Hospital and the Kyorin University School of Medicine in Japan.

Health examination

The health check-up consisted of a questionnaire that assessed demographic and lifestyle-related factors, along with the following measurements and tests: height, weight, blood pressure, pulse rate, IOP, refractive error (spherical equivalent), hematological and serum biochemistry, chest $\mathrm{X}$-rays, electrocardiography, and fundus photography. All subjects were requested not to consume any food or alcohol after 9 p.m. on the day before the examination. The topics covered in the questionnaire included: age, marital status, occupation, residence, current status and past medication history, family medical history, smoking history and number of cigarette smoking per day, drinking history, and exercise habits. Alcohol consumption was classified into the following four categories: never or seldom, several times per month, several times per week, every day. Blood pressure was measured with a sphygmomanometer using the right arm; two consecutive measurements were taken after each subject had rested in a sitting position for at least $5 \mathrm{~min}$. IOP was measured using a non-contact tonometer (NT-3000; Nidek, Japan) and three consecutive measurements were taken for each eye. Refractive error was measured with auto refractometry (ARK-900; Nidek, Japan) three times and the average of the three measurement values was recorded.

\section{Statistical analyses}

Systolic blood pressure (SBP) and diastolic blood pressure (DBP) values for each subject were calculated as the mean of the two measurements. For IOP, the mean of the three measurements was calculated for each eye; however, since there was a strong correlation $(r=0.84)$ between the mean IOP of the right and left eyes in each individual, the mean of these two values was used as a single measure of IOP. The associations of age with IOP, SBP, DBP, and bodymass index (BMI) - calculated as weight $(\mathrm{kg}) / \mathrm{height}$ squared $\left(\mathrm{m}^{2}\right)$-were determined by comparing the mean values of these four parameters among four age groups ( $<40$ years, $40-49$ years, $50-59$ years, and $\geq 60$ years) by sex, using the Bonferroni multiple-comparison method [26]. The Student $t$ test was used to analyze differences in mean IOP, SBP, DBP, and BMI between the two sexes by age group.

The associations between IOP and various demographic and lifestyle-related factors were analyzed using a regression analysis, then the multivariate standardized partial regression coefficients of the following independent variables were determined by multiple regression: age, SBP (model 1) or DBP (model 2), BMI, number of cigarettes smoked per day (nonsmoker, 1-20 per day, $\geq 21$ per day), alcohol consumption (never or seldom $=0$, several times per month $=1$, several times per week $=2$, every day $=3$ ), and regular exercise $($ no $=0$, yes $=1$ ). Next, the adjusted mean levels of IOP and multivariate odds ratios (ORs) were calculated from analyses of covariance 
and multiple logistic regression analyses, respectively. The $95 \%$ confidence interval (CI) for each OR was calculated.

For the analyses of the association of smoking with IOP and blood viscosity, firstly, the adjusted mean IOP and hematocrit values calculated by analysis of covariance were compared among the three categories of number of cigarette smoking (nonsmoker, 1-20 per day, $\geq 21$ per day) in both sexes. Secondly, to analyze the interrelationships of IOP, blood viscosity, and smoking, the adjusted mean IOP values calculated by analysis of covariance were compared among the four groups classified by smoking habit (nonsmoker or smoker) and hematocrit level; subjects were divided into two groups by hematocrit levels to equalize the number of subjects in both groups in both sexes All analyses were conducted using the SAS statistical software package, version 8.2 [27].

\section{Results}

The relationships between age and IOP, SBP, DBP, and BMI are shown in Table 1. The mean IOP was highest in the $<40$ age group for both sexes. In both sexes, the highest mean SBP, DBP, and BMI values were found in the age group of $\geq 60,50-59$, and 50-59, respectively. All parameters measured were significantly higher in men than in women (IOP, $P<0.05$; SBP, DBP, and BMI; $P<0.01)$. The Bonferroni multiple-comparison analysis revealed that the mean IOP was significantly lower in the $\geq 60$ age group than in the $<40$ age group in both sexes $(P<0.05)$.

Table 2 shows the univariate and multivariate standardized partial regression coefficients of demographic and lifestyle-related factors for IOP according to a regression analysis. Age and regular exercise had a negative association with IOP in men $(P<0.01$ and 0.18 , respectively) and women $(P<0.01$ and 0.09 , respectively). On the other hand, SBP, DBP, BMI, and number of cigarettes smoked per day had a significant positive association with IOP in men $(P \leq 0.05)$. In women also, SBP, DBP, and BMI had a significant positive association with IOP $(P<0.05)$. After adjusting for the other independent variables, except for the corresponding demographic and lifestyle-related factors, SBP, DBP, BMI, and number of cigarettes smoked per day had a significant positive association with IOP in men $(P<0.05)$. In women also, SBP, DBP and BMI had a significant positive association with IOP $(P<0.05$, with the exception of BMI in model 2 for women where $P=0.06$ ). On the contrary, age had a significant negative association with IOP in both sexes $(P<0.01)$.

Table 3 shows the adjusted mean IOP values and the multivariate ORs with $95 \%$ CIs for IOP according to the

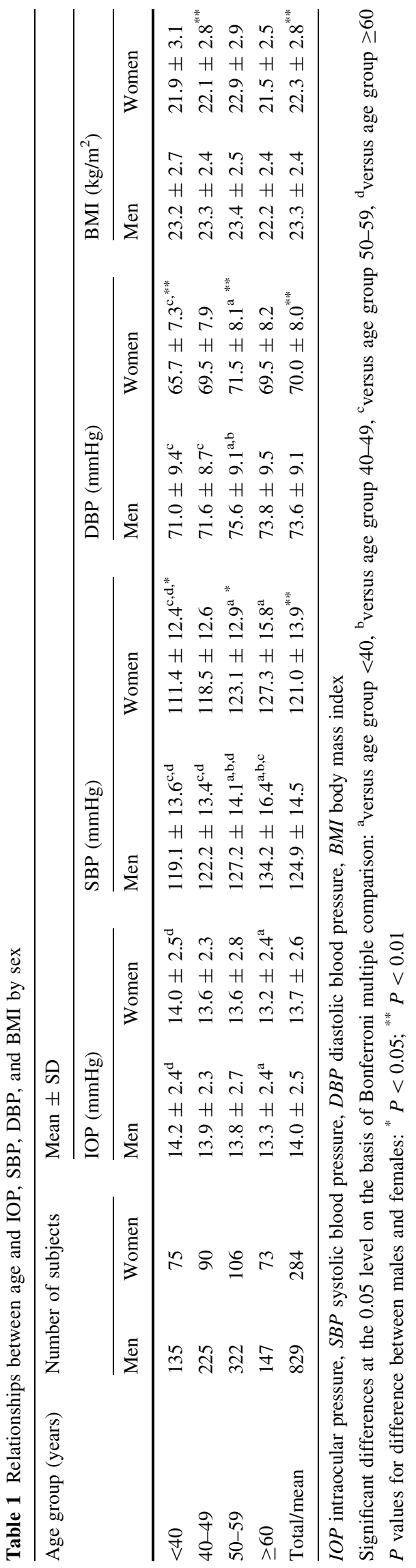


Table 2 Univariate and multivariate standardized partial regression coefficients for IOP according to multiple regression analysis

\begin{tabular}{|c|c|c|c|c|c|c|c|c|c|c|c|c|}
\hline \multirow[t]{4}{*}{ Variables $^{\dagger}$} & \multicolumn{6}{|l|}{ Men } & \multicolumn{6}{|l|}{ Women } \\
\hline & \multirow{2}{*}{\multicolumn{2}{|c|}{$\begin{array}{l}\text { Univariate } \\
\text { standardized } \\
\text { regression } \\
\text { coefficient }\end{array}$}} & \multicolumn{4}{|c|}{$\begin{array}{l}\text { Multivariate standardized partial } \\
\text { regression coefficient }\end{array}$} & \multirow{2}{*}{\multicolumn{2}{|c|}{$\begin{array}{l}\text { Univariate } \\
\text { standardized } \\
\text { regression } \\
\text { coefficient }\end{array}$}} & \multicolumn{4}{|c|}{$\begin{array}{l}\text { Multivariate standardized partial } \\
\text { regression coefficient }\end{array}$} \\
\hline & & & \multicolumn{2}{|l|}{ Model 1} & \multicolumn{2}{|l|}{ Model 2} & & & \multicolumn{2}{|l|}{ Model 1} & \multicolumn{2}{|l|}{ Model 2} \\
\hline & & $P$ value & & $P$ value & & $P$ value & & $P$ value & & $P$ value & & $P$ value \\
\hline Age (years) & -0.279 & $<0.01$ & -0.329 & $<0.01$ & -0.311 & $<0.01$ & -0.227 & $<0.01$ & -0.295 & $<0.01$ & -0.292 & $<0.01$ \\
\hline $\mathrm{SBP}(\mathrm{mmHg})^{*}$ & 0.154 & $<0.01$ & 0.205 & $<0.01$ & & & 0.155 & 0.03 & 0.209 & 0.03 & & \\
\hline $\mathrm{DBP}(\mathrm{mmHg})^{*}$ & 0.189 & $<0.01$ & & & 0.264 & $<0.01$ & 0.204 & 0.02 & & & 0.278 & 0.01 \\
\hline Pulse rate $(/ \mathrm{min})$ & 0.020 & 0.22 & & & & & 0.035 & 0.19 & & & & \\
\hline BMI $\left(\mathrm{kg} / \mathrm{m}^{2}\right)$ & 0.207 & 0.01 & 0.144 & $<0.01$ & 0.135 & 0.03 & 0.229 & 0.04 & 0.190 & 0.03 & 0.166 & 0.06 \\
\hline $\begin{array}{l}\text { Refractive error } \\
\text { (diopter) }\end{array}$ & 0.144 & 0.25 & & & & & 0.166 & 0.33 & & & & \\
\hline Cigarette smoking & 0.170 & 0.05 & 0.143 & 0.03 & 0.149 & 0.02 & 0.111 & 0.16 & 0.155 & 0.17 & 0.160 & 0.13 \\
\hline Alcohol consumption & 0.152 & 0.10 & 0.125 & 0.09 & 0.118 & 0.06 & 0.095 & 0.21 & 0.097 & 0.30 & 0.086 & 0.22 \\
\hline Regular exercise & -0.044 & 0.18 & 0.024 & 0.52 & 0.028 & 0.44 & -0.032 & 0.09 & -0.048 & 0.46 & -0.060 & 0.35 \\
\hline
\end{tabular}

$I O P$ intraocular pressure, SBP systolic blood pressure, DBP diastolic blood pressure, $B M I$ body mass index

Cigarette smoking: number of cigarettes smoked per day

Alcohol consumption: never or seldom $=0$, several times per month $=1$, several times per week $=2$, every day $=3$

Regular exercise: no $=0$; yes $=1$

$\dagger$ Age, SBP (model 1) or DBP (model 2), number of cigarettes consumed per day, alcohol consumption (never or seldom $=0$, several times per month $=1$, several times per week $=2$, everyday $=3$ ), and regular exercise (no $=0$; yes $=1$ ) were added as independent

* Age, BMI, number of cigarettes consumed per day, alcohol consumption (never or seldom $=0$, several times per month $=1$, several times per week $=2$, every day $=3$ ), and regular exercise $($ no $=0$; yes $=1)$ were added as independent variables

Table 3 Adjusted mean levels of IOP and multivariate ORs with $95 \%$ CIs for IOP by number of cigarettes consumed per day

\begin{tabular}{|c|c|c|c|c|}
\hline \multirow[t]{2}{*}{ Number of cigarettes per day } & \multirow[t]{2}{*}{ Number $(\%)$ of subjects } & \multirow{2}{*}{ Mean $( \pm \mathrm{SE}) \mathrm{IOP}^{\dagger}(\mathrm{mmHg})$} & \multicolumn{2}{|c|}{ Multivariate $\mathrm{ORs}^{\dagger}$ for IOP } \\
\hline & & & ORs & $95 \%$ CIs \\
\hline \multicolumn{5}{|l|}{ Men } \\
\hline 0 & $484(58.4)$ & $13.8 \pm 0.1$ & 1.00 & (Reference) \\
\hline $1-20$ & $213(25.7)$ & $14.1 \pm 0.2$ & 1.05 & $0.89-1.40$ \\
\hline$\geq 21$ & $132(15.9)$ & $14.4 \pm 0.3$ & 1.09 & $0.91-1.71$ \\
\hline$P$ value for trend & & 0.01 & 0.06 & \\
\hline \multicolumn{5}{|l|}{ Women } \\
\hline 0 & $244(85.9)$ & $13.6 \pm 0.2$ & 1.00 & (Reference) \\
\hline $1-20$ & $31(10.9)$ & $14.0 \pm 0.5$ & 1.03 & $0.46-5.63$ \\
\hline$\geq 21$ & $9(3.2)$ & $13.7 \pm 1.1$ & 0.99 & $0.38-9.04$ \\
\hline$P$ value for trend & & 0.39 & 0.52 & \\
\hline
\end{tabular}

IOP intraocular pressure, ORs odds ratios, CIs confidence intervals

$\dagger$ Mean IOP levels and multivariate ORs were adjusted for age, systolic blood pressure, body mass index alcohol consumption (never or seldom $=0$; several times per month $=1$; several times per week $=2$ everyday $=3$ ), and regular exercise $($ no $=0 ;$ yes $=1$ )

three categories of number of cigarettes smoked per day. In men, the adjusted mean IOP and the multivariate ORs for IOP increased with increasing cigarette consumption $(P$ for trend $=0.01$ and 0.06 , respectively).
Table 4 shows the adjusted mean levels of IOP and hematocrit from the analysis covariance, among the three categories of number of cigarettes smoked per day. The adjusted mean IOP and the adjusted mean hematocrit 
Table 4 Adjusted mean levels of IOP and Ht by number of cigarettes consumed per day

\begin{tabular}{|c|c|c|c|c|c|c|c|}
\hline \multirow[t]{2}{*}{ Number of cigarettes per day } & \multirow[t]{2}{*}{ Number $(\%)$ of subjects } & \multirow[t]{2}{*}{ Mean $( \pm$ SE) IOP $(\mathrm{mmHg})$} & \multirow[t]{2}{*}{ Mean $( \pm \mathrm{SE}) \mathrm{Ht}(\%)$} & \multicolumn{2}{|c|}{$\begin{array}{l}P \text { value based } \\
\text { on } F \text { value }\end{array}$} & \multicolumn{2}{|c|}{$\begin{array}{l}P \text { value for } \\
\text { trend }\end{array}$} \\
\hline & & & & IOP & $\mathrm{Ht}$ & IOP & $\mathrm{Ht}$ \\
\hline \multicolumn{8}{|l|}{ Men } \\
\hline 0 & $484(58.4)$ & $13.8 \pm 0.1$ & $43.5 \pm 0.2$ & & & & \\
\hline $1-20$ & $213(25.7)$ & $14.1 \pm 0.2$ & $44.1 \pm 0.2$ & 0.01 & $<0.01$ & 0.04 & $<0.01$ \\
\hline$\geq 21$ & $132(15.9)$ & $14.4 \pm 0.3$ & $44.7 \pm 0.3$ & & & & \\
\hline \multicolumn{8}{|l|}{ Women } \\
\hline 0 & $244(85.9)$ & $13.6 \pm 0.2$ & $39.1 \pm 0.2$ & & & & \\
\hline $1-20$ & $31(10.9)$ & $14.0 \pm 0.5$ & $39.6 \pm 0.6$ & 0.12 & 0.24 & 0.39 & 0.04 \\
\hline$\geq 21$ & $9(3.2)$ & $13.7 \pm 1.1$ & $41.2 \pm 1.2$ & & & & \\
\hline
\end{tabular}

$I O P$ intraocular pressure, $\mathrm{Ht}$ hematocrit

Mean IOP and Ht levels were adjusted for age, systolic blood pressure, body mass index, alcohol consumption (never or seldom: 0; several times/ month: 1; several times/week: 2; everyday: 3 ), and regular exercise $($ no $=0$; yes $=1$ )

Table 5 Adjusted mean levels of IOP by smoking habit and Ht levels

\begin{tabular}{|c|c|c|c|c|c|}
\hline \multirow{2}{*}{$\begin{array}{l}\text { Variables } \\
\text { Men }\end{array}$} & \multirow[t]{2}{*}{ Number $(\%)$ of subjects } & \multirow[t]{2}{*}{ Mean $( \pm$ SE) IOP $(\mathrm{mmHg})$} & \multicolumn{3}{|c|}{$\begin{array}{l}P \text { value for the difference in mean IOP } \\
\text { between each group }\end{array}$} \\
\hline & & & M1 & M2 & M3 \\
\hline M1: Non smoker and $\mathrm{Ht}<44.1 \%$ & $265(32.0)$ & $13.8 \pm 0.2$ & - & & \\
\hline M2: Non smoker and $\mathrm{Ht} \geq 44.1 \%$ & $219(26.4)$ & $13.7 \pm 0.2$ & 0.68 & - & \\
\hline M3: Habitual smoker and $\mathrm{Ht}<44.1 \%$ & $148(17.9)$ & $14.3 \pm 0.3$ & 0.03 & 0.04 & - \\
\hline M4: Habitual smoker and $\mathrm{Ht} \geq 44.1 \%$ & $197(23.7)$ & $14.1 \pm 0.2$ & 0.08 & 0.11 & 0.47 \\
\hline Women & & & W1 & W2 & W3 \\
\hline W1: Non smoker and $\mathrm{Ht}<39.5 \%$ & $124(43.7)$ & $13.5 \pm 0.3$ & - & & \\
\hline W2: Non smoker and $\mathrm{Ht} \geq 39.5 \%$ & $120(42.2)$ & $13.7 \pm 0.3$ & 0.46 & - & \\
\hline W3: Habitual smoker and $\mathrm{Ht}<39.5 \%$ & $19(6.7)$ & $13.9 \pm 0.8$ & 0.29 & 0.14 & - \\
\hline W4: Habitual smoker and $\mathrm{Ht} \geq 39.5 \%$ & $21(7.4)$ & $13.8 \pm 0.7$ & 0.42 & 0.24 & 0.73 \\
\hline
\end{tabular}

IOP intraocular pressure, $H t$ hematocrit

Mean IOP and Ht levels were adjusted for age, systolic blood pressure, body mass index, alcohol consumption (never or seldom: 0; several times/ month: 1; several times/week: 2 ; every day: 3$)$, and regular exercise $($ no $=0$; yes $=1)$

values both increased with increasing cigarette consumption in men ( $P$ for trend $=0.04$ and $<0.01$, respectively). In women, only the adjusted mean hematocrit value increased as cigarette consumption increased $(P$ for trend $=0.04$ ).

Table 5 shows the adjusted mean levels of IOP from the analysis covariance, among the four groups classified by smoking habit and hematocrit level. The adjusted mean IOP values were higher in smokers than in nonsmokers, regardless of the hematocrit level; however, these trends did not reach statistically significant levels.

\section{Discussion}

In the present study, positive associations of IOP with SBP, DBP, and BMI were found. These positive associations were consist with several previous studies in Caucasian and Asian population. According to the relationship on the mechanism of the BP-IOP and the BMI-IOP (Fig. 1) [9, 28-31] it is suggested that high BP, especially elevated SBP, might elevate IOP by increasing ultrafiltration of the aqueous humor through the elevation of ciliary artery pressure $[28,29]$. On the other hand, weight gain reduces the aqueous-humor outflow caused by elevated intraorbital pressure associated with excessive intraorbital fatty tissue, or increases the outflow resistance of the episcleral vein due to an increase in blood viscosity accompanied by hemorheological parameters such as hematocrit and fibrinogen $[9,30,31]$.

The mean IOP across the group as a whole, measured using a non-contact tonometer, decreased with age and subjects $\geq 60$ years of age showed the lowest mean IOP in both sexes. Several previous studies of Europeans and 

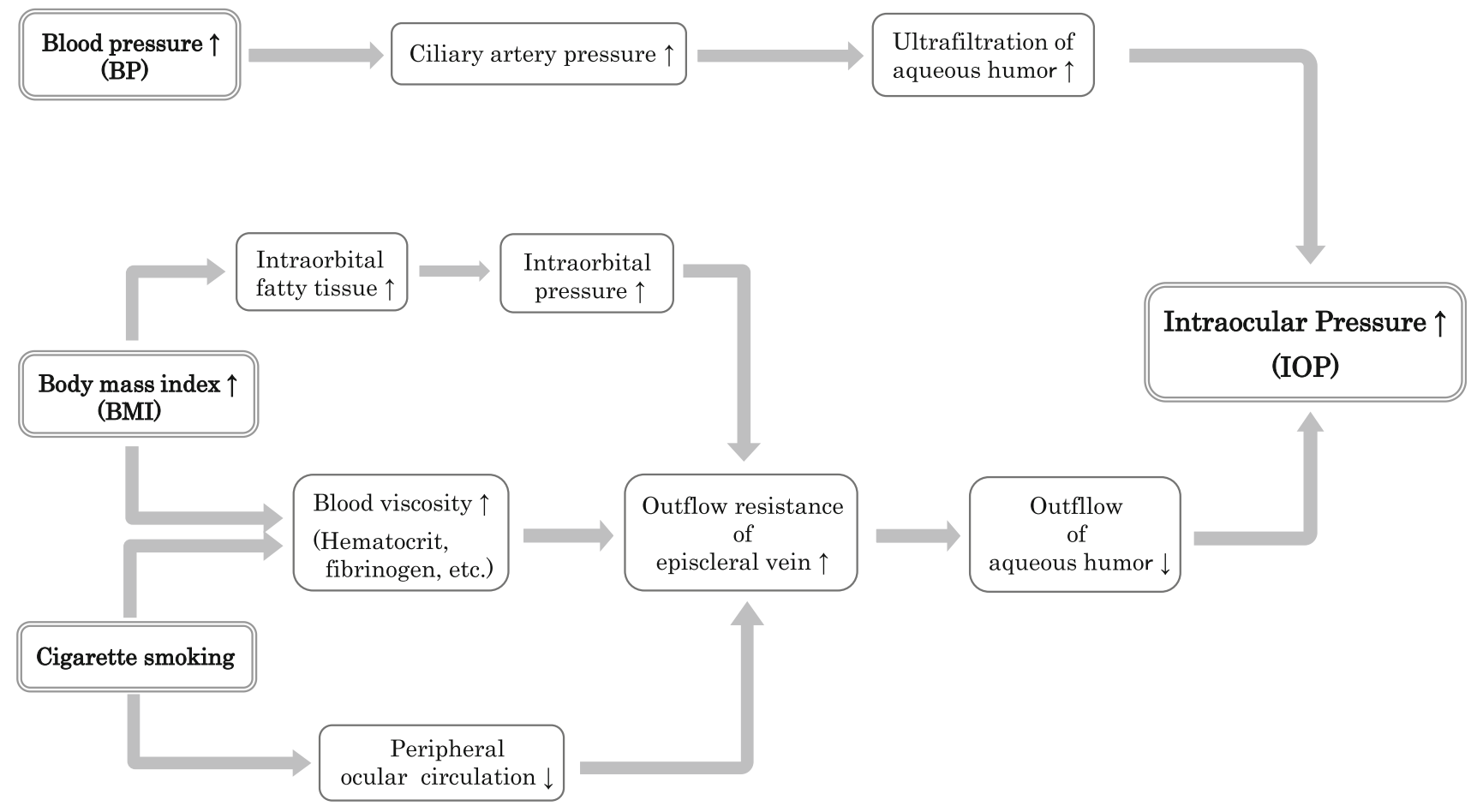

Fig. 1 Relationship on the mechanism of BP-IOP, BMI-IOP, and smoking-IOP

Americans, with the exception of studies in Asian countries, have reported an increase in IOP after the age of 40 years and a decrease in IOP among elderly populations. By contrast, IOP was found to decrease with age in Asian populations [32-34]. The association of IOP with age, BP, and BMI observed in this study was consistent with that found in several Asian countries. However, when the positive age-BP and BP-IOP associations were taken into accounts, the inverse age-IOP association appeared to be incompatible. Shiose [32] suggested that the ocular hypotensive effect of aging might outweigh the ocular hypertensive effects of hypertension and obesity in Asians. Conversely, the ocular hypertensive effects of hypertension and obesity might outweigh the ocular hypotensive effect of aging in Europeans and Americans, leading to the observed increase in IOP after middle age. Furthermore, it was proposed that a decrease in IOP in the elderly might be caused by a reduction in the number of obese hypertensive subjects because of death from cardiovascular accidentsthat is, a "survival effect" of healthy individuals. This theory was supported by the report by Toris [35], which revealed no significant difference in mean IOP between healthy American subjects in their 20s and those aged $\geq 60$ years.

Our study showed that smoking was significantly associated with elevated IOP in men. This significant positive association was not found in women. However, because of the relatively small sample size of women and the considerably small proportions of smokers in women, this association may not have reached a statistically significant level in women. Even more importantly, we should also point out at least three major limitations that our study might have had. Firstly, it should be considered that the IOP values used in this study were obtained by the noncontact tonometer, which is less accurate than the Goldmann applanation tonometer. Secondary, the distribution of IOP in this study might not represent that of the general population. Therefore, the distribution of IOP in this study may be somewhat skewed as compared with that of the general population. All the subjects in this study were the clients who had consulted a general hospital. The elderly individuals might be more likely to visit hospital for an annual health check-up than the healthy younger individuals. This implies that the prevalence of elevated IOP in this study could be overestimated compared with that of general population, because the prevalence of glaucoma including subclinical glaucoma increase with aging. On the other hand, ocular hypertensive patients who had been diagnosed as a pre-glaucoma stage and followed by not medication but periodical ophthalmological examination of optic nerve and visual field under hospital/clinic care, who might have been less likely to visit an annual health checkup or have passed up the ophthalmological examination even if they have visited, could be inevitably excluded from the subjects. Such selection bias might have led to the underestimation of the prevalence of elevated IOP for the 
general population. However, at least the latter selection bias may be kept to a minimum, because the number of the subjects who had refused to receive the ophthalmological examination was very small $(0.68 \%)$. Finally, we used cross-sectional analyses to confirm the positive association between IOP and BP, BMI, and smoking, as have been reported in previous epidemiological studies $[7,9,11,28$ 31]. These results from cross-sectional studies have also demonstrated by longitudinal studies on positive BP-IOP and BMI-IOP relationships in Japanese [36] and Western $[37,38]$ populations. However, because there is no longitudinal study on the smoking-IOP relationship, further prospective studies are required for reliable evidence of the effect of cigarette consumption on IOP.

Although other studies have also reported a positive association of smoking with IOP [7, 9, 11], the mechanisms remain unclear. Blood pressure was included as a covariate in the present analyses; therefore, the effects of smoking on blood pressure cannot account for the positive association between cigarette consumption and IOP. One possible explanation is that the outflow resistance of the aqueous humor through the blood flow reduction in the peripheral ocular circulation or the increase in blood viscosity accompanied by hemorheological parameters caused by smoking (such as hematocrit and fibrinogen, which has been documented in several studies) might elevate IOP (Fig. 1). Actually, experimental reports human and animal models [39-41] have shown the acute effect of smoking or inhalation of cigarette smoke on the ocular circulation. Morgado [39] and Robinson [40], using laser Doppler velocimetry and retinal photography, and the blue field simulation technique, respectively, reported that retinal blood flow rate decreased by $10-12 \%$ in habitual smokers. Also reported, in rabbits, a $20 \%$ reduction in choroidal blood flow was caused by a single inhalation of cigarette smoke [41]. This blood flow reduction in the peripheral ocular circulation caused by cigarette smoking might elevate IOP resulting from an increase in the outflow resistance of the aqueous humor. Previous studies also revealed that white cell counts, hemoglobin, hematocrit, and fibrinogen levels are significantly higher in smokers than in nonsmokers, that there is a dose-effect relationship between the number of cigarettes consumed and the increase in these hemorheological parameters, and that these parameters decrease if an individual stops smoking [23-25].

We therefore attempted to clarify the interrelationships between IOP, blood viscosity, and smoking. Although smoking was associated with both high IOP and high hematocrit, these analyses failed to detect evidence of an effect of increased blood viscosity caused by smoking on IOP. We therefore suggest that the positive smoking-IOP relationship might be more directly or strongly ensured from an effect on the ocular circulation than from an effect on blood viscosity. Further investigations will be necessary to clarify the mechanism of the smoking-IOP association.

In conclusion, the results of this study suggest that smoking might be related to the elevation of IOP in middleaged and older Japanese men. Glaucoma is the second leading cause of blindness worldwide. It is estimated that the number of people with glaucoma will be 80 million in 2020, and more than $70 \%$ of those will have OAG [42]. Because high IOP is not only a risk factor for OAG but also influences the progression of visual-field defects in OAG patients, particularly those with NTG, the prohibition of smoking might be one of the important lifestyle factors for Japanese patients with OAG or ocular hypertension as they have a higher incidence of NTG than Europeans and Americans.

Acknowledgments This study was supported by a Grant-in-Aid from the Ministry of Education, Culture, Sports, Science and Technology of Japan (No. 22790570).

Conflicts of interest The authors declare that they have no conflict of interest.

\section{References}

1. World Health Organization. WHO report on the global tobacco epidemic, 2011: warning about the dangers of tobacco. Geneva, Switzerland: World Health Organization; 2011.

2. Wilson MR, Hertzmark E, Walker AM, Childs-Shaw K, Epstein DL. A case-control study of risk factors in open angle glaucoma. Arch Ophthalmol. 1987;105:1066-71.

3. Kang JH, Pasquale LR, Rosner BA, Willett WC, Egan KM, Faberowski N, et al. Prospective study of cigarette smoking and the risk of primary open-angle glaucoma. Arch Ophthalmol. 2003;121:1762-8.

4. Bonovas S, Filioussi K, Tsantes A, Peponis V. Epidemiological association between cigarette smoking and primary open-angle glaucoma: a meta-analysis. Public Health. 2004;118:256-61.

5. Edwards R, Thornton J, Ajit R, Harrison RA, Kelly SP. Cigarette smoking and primary open angle glaucoma: a systematic review. J Glaucoma. 2008;17:558-66.

6. Wise LA, Rosenberg L, Radin RG, Mattox C, Yang EB, Palmer JR, et al. A prospective study of diabetes, lifestyle factors, and glaucoma among African-American women. Ann Epidemiol. 2011;21:430-9.

7. Morgan RW, Drance SM. Chronic open-angle glaucoma and ocular hypertension: an epidemiological study. Br J Ophthalmol. 1975;59:211-5.

8. Klein BE, Klein R, Linton KL. Intraocular pressure in an American community: the Beaver Dam eye study. Invest Ophthalmol Vis Sci. 1992;33:2224-8.

9. Wu SY, Leske MC. Associations with intraocular pressure in the Barbados eye study. Arch Ophthalmol. 1997;115:1572-6.

10. Weih LM, Mukesh BN, McCarty CA, Taylor HR. Association of demographic, familial, medical, and ocular factors with intraocular pressure. Arch Ophthalmol. 2001;119:875-80.

11. Lee AJ, Rochtchina E, Wang JJ, Healey PR, Mitchell P. Does smoking affect intraocular pressure? Findings from the Blue Mountains eye study. J Glaucoma. 2003;12:209-12. 
12. Leske MC. The epidemiology of open-angle glaucoma: a review. Am J Epidemiol. 1983;118:166-91.

13. Musch DC, Gillespie BW, Lichter PR, Niziol LM, Janz NK, CIGTS Study Investigators. Visual field progression in the collaborative initial glaucoma treatment study the impact of treatment and other baseline factors. Ophthalmology. 2009;116: 200-7.

14. Jonas JB, Gusek GC, Naumann GO. Optic disk morphometry in high myopia. Graefes Arch Clin Exp Ophthalmol. 1988;226: 587-90.

15. Suzuki Y, Iwase A, Araie M, Yamamoto T, Abe H, Shirato S, Tajimi Study Group, et al. Risk factors for open-angle glaucoma: in Japanese population: the Tajimi study. Ophthalmology. 2006;113:1613-7.

16. Leske MC, Heijl A, Hyman L, Bengtsson B, Dong L, Yang Z, EMGT Group. Predictors of long-term progression in the early manifest glaucoma trial. Ophthalmology. 2007;114:1965-72.

17. Shiose Y, Kitazawa Y, Tsukahara S, Akamatsu T, Mizokami K, Futa R, et al. Epidemiology of glaucoma in Japan: a nationwide glaucoma survey. Jpn J Ophthalmol. 1991;35:133-55.

18. Iwase A, Suzuki Y, Araie M, Yamamoto T, Abe H, Shirato S, Tajimi Study Group, Japan Glaucoma Society, et al. The prevalence of primary open-angle glaucoma in Japanese: the Tajimi Study. Ophthalmology. 2004;111:1641-8.

19. Yamamoto T, Iwase A, Araie M, Suzuki Y, Abe H, Shirato S, Tajimi Study Group, Japan Glaucoma Society, et al. The Tajimi Study report 2: prevalence of primary angle closure and secondary glaucoma in a Japanese population. Ophthalmology. 2005;112:1661-9.

20. Sommer A, Tielsch JM, Katz J, Quigley HA, Gottsch JD, Javitt J, et al. Relationship between intraocular pressure and primary open angle glaucoma among white and black Americans: the Baltimore Eye Survey. Arch Ophthalmol. 1991;109:1090-5.

21. Tielsch JM, Sommer A, Katz J, Royall RM, Quigley HA, Javitt J. Racial variations in the prevalence of primary open-angle glaucoma. The Baltimore Eye Survey. JAMA. 1991;266:369-74.

22. Mitchell P, Smith W, Attebo K, Healey PR. Prevalence of openangle glaucoma in Australia. The Blue Mountains Eye Study. Ophthalmology. 1996;103:1661-9.

23. Eisen ME, Hammond EC. The effect of smoking on packed cell volume, red blood cell counts, haemoglobin and platelet counts. Can Med Assoc J. 1956;75:520-3.

24. Okuno T. Smoking and blood changes. JAMA. 1973;225:1387-8.

25. Dodsworth H, Dean A, Broom G. Effects of smoking and the pill on the blood count. Br J Haematol. 1981;49:484-8.

26. Ingelfinger JA, Mosteller F, Thibodeau LA, Ware JH. What are $\mathrm{P}$ values? In: Ingelfinger JA, Mosteller F, Thibodeau LA, Ware JH, editors. Biostatistics in Clinical Medicine. 3rd ed. New York: McGraw-Hill; 1994. p. 155-73.
27. SAS Institute Inc. SAS/STAT User's Guide, Version 6.12. Cary, NC: SAS Institute Inc.; 1997.

28. Shiose $Y$. The aging effect on intraocular pressure in an apparently normal population. Arch Ophthalmol. 1984;102:883-7.

29. Ganley JP. Epidemiological aspects of ocular hypertension. Surv Ophthalmol. 1980;25:130-5.

30. Bulpitt CJ, Hodes C, Everitt MG. Intraocular pressure and systemic blood pressure in the elderly. Br J Ophthalmol. 1975; 59:717-20.

31. Dielemans I, Vingerling JR, Algra D, Hofman A, Grobbee DE, de Jong PT. Primary open-angle glaucoma. Intraocular pressure and systemic blood pressure in the general elderly population. The Rotterdam Study. Ophthalmology. 1995;102:54-60.

32. Shiose Y. Intraocular pressure: new perspectives. Surv Ophthalmol. 1990;34:413-35.

33. Kawase $\mathrm{K}$, Tomidokoro A, Araie M, Iwase A, Yamamoto T, Tajimi Study Group, Japan Glaucoma Society. Ocular and systemic factors related to intraocular pressure in Japanese adults: the Tajimi study. Br J Ophthalmol. 2008;92:1175-9.

34. Suh W, Kee C, Namil Study Group, Korean Glaucoma Society. The distribution of intraocular pressure in urban and in rural populations: the Namil study in South Korea. Am J Ophthalmol. 2012;154:99-106.

35. Toris CB, Yablonski ME, Wang YL, Camras CB. Aqueous humor dynamics in the aging human eye. Am J Ophthalmol. 1999;127:407-12.

36. Nomura H, Shimokata H, Ando F, Miyake Y, Kuzuya F. Agerelated changes in intraocular pressure in a large Japanese population: a cross-sectional and longitudinal study. Ophthalmology. 1999;106:2016-22.

37. Klein BE, Klein R, Knudtson MD. Intraocular pressure and systemic blood pressure: longitudinal perspective: the Beaver Dam Eye Study. Br J Ophthalmol. 2005;89:284-7.

38. Wu SY, Nemesure B, Hennis A, Leske MC, Barbados Eye Studies Group. Nine-year changes in intraocular pressure: the Barbados Eye Studies. Arch Ophthalmol. 2006;124:1631-6.

39. Morgado PB, Chen HC, Patel V, Herbert L, Kohner EM. The acute effect of smoking on retinal blood flow in subjects with and without diabetes. Ophthalmology. 1994;101:1220-6.

40. Robinson F, Petrig BL, Riva CE. The acute effect of cigarette smoking on macular capillary blood flow in humans. Invest Ophthalmol Vis Sci. 1985;26:609-13.

41. Inoue Y. Effects of cigarette smoking on choroidal circulation. I. Acute phase. J Jpn Ophthalmol Soc. 1985;89:1236-41.

42. Quigley HA, Broman AT. The number of people with glaucoma worldwide in 2010 and 2020. Br J Ophthalmol. 2006;90:262-7. 